Check for updates

Cite this: RSC Adv., 2019, 9, 32854

\title{
The purification and identification of immunoregulatory peptides from oyster (Crassostrea hongkongensis) enzymatic hydrolysate
}

\author{
Wan Li, tae Cheng Xu, D $\uparrow^{\text {ae }}$ Chaohua Zhang, *abcde Wenhong Cao, abcde \\ Xiaoming Qin, ${ }^{\text {abcde }}$ Jialong Gao abcde and Huina Zheng ${ }^{\text {abcde }}$
}

Oysters, favored as a delicious seafood by people worldwide, contain various nutritional components, especially proteins. In this work, the immunoregulatory peptides were isolated and purified from oyster enzymatic hydrolysate by utilizing anion exchange chromatography and RP-HPLC, and were identified via LC-MS/MS. A proliferation assay, a phagocytosis assay, and TNF- $\alpha$ production, NO production and IL6 production assays were used to examine the immunoregulatory effects of the two identified peptides. The results indicate that the peptides, DNSIAMESMK (P1) and LLQLGSGR (P2), increased the proliferation rate of macrophages, TNF- $\alpha$ and NO production, IL-6 production, and the phagocytosis ability, but to different degrees; P2, with more hydrophobic amino acids, was more potent than P1. This suggested that these peptides might be potential candidates for developing immunoregulatory functional foods and nutraceuticals.

Received 6th June 2019

Accepted 6th September 2019

DOI: $10.1039 / c 9 r a 04255 e$

rsc.li/rsc-advances

\section{Introduction}

In recent years, scientists worldwide have gradually shifted their attention to the vast expanse of the ocean to discover various bioactive compounds from marine resources, due to the highly diversified environment in ocean water. ${ }^{1,2}$

Oysters are a kind of popular seafood; the total production of oysters around the world is reported to be around 5 million tonnes per year, and oysters have already become a valuable commercial product for many countries. ${ }^{3}$ Due to the increased need in the market for functional products, many biological functions derived from oysters have been discovered in recent years, such as antioxidant, ${ }^{4-8}$ antihypertensive, ${ }^{9}$ antimicrobial, ${ }^{7,10}$ HIV-1 protease inhibitory, ${ }^{11}$ anti-fatigue, ${ }^{12}$ aphrodisiac, ${ }^{4}$ anticancer, ${ }^{8,13}$ and immune regulation. ${ }^{14-17}$ The oysterderived bioactive compounds responsible for their immunoregulatory activity are mainly polysaccharides and peptides,

${ }^{a}$ College of Food Science and Technology, Guangdong Ocean University, A321 Food Science Building, Zhanjiang 524088, China. E-mail: zhangch2@139.com; Tel: +86 13902501963

${ }^{b}$ National Research and Development Branch Center for Shellfish Processing, Zhanjiang 524088, China

${ }^{c}$ Guangdong Provincial Key Laboratory of Aquatic Products Processing and Safety, Zhanjiang 524088, China

${ }^{d}$ Key Laboratory of Advanced Processing of Aquatic Product of Guangdong Higher Education Institution, Zhanjiang 524088, China

${ }^{e}$ Shenzhen Institute of Guangdong Ocean University, Shenzhen 518108, China

$\dagger$ Wan Li and Cheng Xu contributed to this article equally. and the mechanisms involved include promoting the proliferation of spleen lymphocytes, regulating antigen-specific $\mathrm{T}$ cell responses, recovering the $\mathrm{T}$ lymphocytes, improving immune cytokines, and increasing the phagocytosis ability. ${ }^{14-17}$

Proteins are the most abundant components in oyster meat on a dry basis, and it has been shown that oyster proteins have excellent quality by analyzing their amino acid profile. ${ }^{18}$ Oyster proteins are obviously a great candidate for obtaining peptides. As far as we know, the samples used for studying the immunoregulatory activity of oyster proteins were mostly extremely complex, such as hydrolysates, and no purified peptides with identified information have been reported yet.

It has been reported that peptides with short sequences ranging from 2 to 10 amino acids are likely to have higher bioavailability in the human body and to exert immunoregulatory activity. ${ }^{19}$ Enzymatic hydrolysis is widely used to breakdown the proteins at some specific sites and to obtain shorter peptides. Considering the complex composition in the enzymatic hydrolysate, it is not possible to determine which part of the hydrolysate is mainly responsible for the immunoregulatory activity. Therefore, the main objective of this research work was to (1) combine multiple techniques (ultrafiltration, ion exchange chromatography, and RP-HPLC) with enzymatic hydrolysis to obtain purified oyster peptides; and (2) to identify characteristics of the peptides and to investigate their mechanisms of immunoregulatory activity. 


\section{Materials and methods}

\subsection{Materials}

Fresh oysters (Crassostrea hongkongensis) were purchased from the local Dongfeng Market in Zhanjiang, China (the shells were removed immediately at the market, and then the soft body was stored at $-20{ }^{\circ} \mathrm{C}$ until use). Animal protease (enzyme activity 23 $\times 10^{4} \mathrm{U} \mathrm{g}^{-1}$, optimal operating conditions are as follows: temperature $50-60{ }^{\circ} \mathrm{C}, \mathrm{pH} 6.0-7.0$, time 5-8 h) was purchased from Pangbo Biological Engineering Co., Ltd. (Nanning, Guangxi, China). RPMI 1640 medium, DMEM medium, and penicillin-streptomycin solution were purchased from Gibco Life Technologies (Grand Island, NY, USA). Lipopolysaccharide (LPS) was purchased from Sigma-Aldrich (St. Louis, Missouri, United States). ConA was purchased from Yuanye Biotechnology (Shanghai, China). Fetal bovine serum was purchased from Gemini Bio-Products (California, USA). Neutral red was purchased from Tianxin Fine Chemicals (Tianjing, China). Cell Counting Kit-8 was obtained from Dojindo Laboratories (Kumamoto Japan). The Griess Reagent System was purchased from Promega Corporation (Wisconsin, USA). Mouse TNF- $\alpha$ and IL-6 were purchased from ExCell Biotech (Shanghai, China). All of the chemicals and reagents were of analytical grade. SPF Kunming mice $(20 \pm 2 \mathrm{~g}$ weight) were obtained from HFK Bioscience (Beijing, China). All animal experiments were approved by the Welfare Committee of the Centre of Experimental Animals, Guangdong, China.

\subsection{Preparation of oyster hydrolysates with low molecular weight (OHLM)}

Oyster meat (1000 g) was chopped into pieces and then mixed with distilled water $(3: 1 \mathrm{v} / \mathrm{w})$. The mixture was homogenized for $1 \mathrm{~min}$ at $8000 \mathrm{rpm}$ using a homogenizer (T18, ULTRATURRAX, Germany). The homogenate was then preheated in a constant temperature shaker at $53{ }^{\circ} \mathrm{C}$ for $5 \mathrm{~min}$. The $\mathrm{pH}$ of the preheated homogenate was adjusted to 7 with the help of a $\mathrm{pH}$ meter (REX PHS-2F, INESA Scientific Instrument, China) and $0.4 \%$ animal protease $(\mathrm{w} / \mathrm{w})$ was added. The hydrolysis reaction lasted for 6 hours, and the enzymes were then inactivated in a boiling water bath for $10 \mathrm{~min}$. The hydrolysate was cooled to room temperature and centrifuged (TDL-5-A, Shanghai, China) at $6500 \mathrm{r} / \mathrm{min}$ for $20 \mathrm{~min}$. The supernatant was collected, and filtered by a $200 \mu \mathrm{m}$ inorganic ceramic membrane using a microfiltration device (WTM-CM-01, Hangzhou, China), and reverse osmosis desalination was performed by using a $100 \mathrm{Da}$ reverse osmosis membrane. The desalinated hydrolysate was further filtered by a $5 \mathrm{kDa}$ spiral-wound membrane, and then vacuum-concentrated (Zhengzhou Greatwall Scientific, China), vacuum freeze-dried (Tokyo Rikakikai Co. Ltd., Japan) and stored at $-20{ }^{\circ} \mathrm{C}$ until use. In addition, the degree of hydrolysis (DH) of the oyster hydrolysate before going through any filtering processes was determined. The total nitrogen and non-protein nitrogen in the oysters were assessed by the Kjeldahl method, while amino acid nitrogen and free-formed amino acid nitrogen were determined by formaldehyde titration. The formula for calculation of the hydrolysis degree is: $\mathrm{DH}(\%)=$ (hydrolyzed peptide bonds/total peptide bonds $) \times 100=\{(\mathrm{B}-\mathrm{C}) /(\mathrm{A}-\mathrm{D})\} \times$ 100 , where $\mathrm{A}$ is the total nitrogen in raw oysters, $\mathrm{B}$ is the amino acid nitrogen in oyster hydrolysate, $\mathrm{C}$ is the free-formed amino acid nitrogen in raw oysters, and $\mathrm{D}$ is the non-protein nitrogen in raw oysters.

\subsection{Evaluation of the molecular weight distribution of peptides in OHLM}

The molecular distribution of the samples was determined by high-performance size-exclusion chromatography. The samples of OHLM were dissolved in distilled water, and applied to a LC20AD HPLC system equipped with a Waters Protein-pak 60A (WAT085250) column, eluted with $0.05 \mathrm{~mol} \mathrm{~L}^{-1}$ Tris-HCl (pH 8.3) at a flow rate of $0.7 \mathrm{~mL} \mathrm{~min}^{-1}$, with the column temperature adjusted to $25{ }^{\circ} \mathrm{C}$ and monitored at $214 \mathrm{~nm}$. Lysozyme (14 300 $\mathrm{Da})$, vitamin B12 (1355.38 Da), $N$-Hippuryl-His-Leu hydrate (429.47 Da), and tyrosine (181.19 Da) were used as standards to calibrate the column and establish a standard curve.

\subsection{Analysis of amino acids of OHLM}

The freeze-dried OHLM mixed with $6 \mathrm{~mol} \mathrm{~L}^{-1} \mathrm{HCl}$ was hydrolyzed at $110{ }^{\circ} \mathrm{C}$ for 22 hours, and then analyzed by an automatic amino acid analyzer (Hitachi High-Technologies Co., Japan). The content of amino acids in the sample was expressed as $\mathrm{g}$ per $100 \mathrm{~g}$.

\subsection{Peptide separation by anion exchange chromatography}

The OHLM (0.5 $\left.\mathrm{mg} \mathrm{mL}^{-1}\right)$ was loaded onto an anion exchange column (Q Sepharose Fast Flow, internal diameter $2.6 \mathrm{~cm}$, length $12.3 \mathrm{~cm}$ ) equilibrated with $0.05 \mathrm{~mol} \mathrm{~L}^{-1}$ Tris- $\mathrm{HCl}(\mathrm{pH} \mathrm{9.0)}$ and eluted with a salt solution $\left(0.5 \mathrm{~mol} \mathrm{~L}{ }^{-1} \mathrm{NaCl}\right)$ in $0.05 \mathrm{~mol} \mathrm{~L}^{-1}$ Tris- $\mathrm{HCl}$ (pH 9.0) at a flow rate of $5.0 \mathrm{~mL} \mathrm{~min}^{-1}$ and monitored at $214 \mathrm{~nm}$. Each fraction was pooled and vacuum freeze-dried for determination of immunoregulatory activity.

\subsection{Peptide purification by reversed-phase high performance liquid chromatography (RP-HPLC)}

The peptide fraction F3 from Q Sepharose Fast Flow, which showed the highest proliferative activity of splenic lymphocytes, was dissolved in distilled water, filtered through $0.22 \mu \mathrm{m}$ filters, and then separated by a YMC-Pack ODS-A C18 column $(5 \mu \mathrm{m}$, $250 \times 20 \mathrm{~mm}$ ). Peptides were eluted with eluent A (ultrapure water), and then with a linear gradient of acetonitrile (5-10\%) at

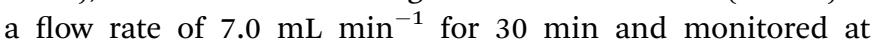
$214 \mathrm{~nm}$. All the fractions were collected for the determination of the immunoregulatory activity.

\subsection{Peptide identification by LC-MS/MS}

The purified peptides were firstly transferred into a SPE column, and $200 \mu \mathrm{L}$ of $2 \%$ acetonitrile $(0.1 \%$ trifluoroacetic acid), $200 \mu \mathrm{L}$ of $50 \%$ acetonitrile ( $0.1 \%$ trifluoroacetic acid), and $50 \mu \mathrm{L}$ of $50 \%$ acetonitrile $(0.1 \%$ trifluoroacetic acid), were added sequentially in order to remove the impurities in the samples. The peptides were then applied to HPLC (LC-1200, Agilent, USA), and the column used in this step is an Acclaim PepMap RSLC C18 (300 
$\mu \mathrm{m}$ i.d. $\times 5 \mathrm{~mm}$, nano Viper). The peptides were eluted with eluent A ( $0.1 \%$ formic acid) and eluent B ( $0.1 \%$ formic acid and

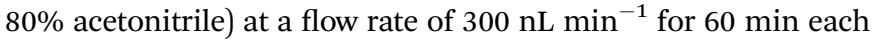
time. The peptides separated by HPLC were then applied to the tandem mass spectrometer (Q Exactive mass spectrometer, Thermo fisher, USA) for peptide identification. The detailed parameters were as follows: (1) peptide mass parameters: resolution, 70 000; AGC target, $3 \times 10^{6}$; maximum IT, in $40 \mathrm{~ms}$; scan range, 50 to $1800 \mathrm{~m} / z$; (2) fragment mass parameters: resolution, 17 500; AGC target, $1 \times 10^{5}$; maximum IT, $60 \mathrm{~ms}$; TopN, 20; NCE/ stepped NCE, 27. The data collected from the tandem mass spectrometer were searched in a database using Mascot software. The parameters used in the database search are as follows: fixed modifications, carbamidomethyl (C); variable modifications, oxidation (M); peptide mass tolerance, 20 ppm; fragment mass tolerance, 0.6 Da; mass values, monoisotopic; significance values below 0.05 are considered statistically significant.

\subsection{Assessment of proliferative activity of splenic lymphocytes of mice}

The spleens of Kunming female mice were removed under sterile conditions, and immediately placed into a dish with $5 \mathrm{~mL}$ PBS, and the spleens were washed with PBS 2-3 times in order to clean away the blood. The spleen then was placed on a 200-mesh sieve, and chopped and ground using scissors. Cell suspensions of splenic lymphocytes from Kunming mice were collected in $15 \mathrm{~mL}$ centrifuge tubes, and then subjected to centrifugation $(1200 \mathrm{~g})$ for $10 \mathrm{~min}$. The supernatant was removed, red blood cell lysis buffer was added, and then the mixture was subjected to centrifugation (1200 g) again for $8 \mathrm{~min}$. The supernatant was removed as above, and then $3 \mathrm{~mL}$ of PBS was added twice to wash away the red blood cell lysis buffer; each time the solution was centrifuged for $6 \mathrm{~min}$. RPMI 1640 was added to make sure that the cell survival rate was more than $95 \%$, and the cell concentration was adjusted to $3.0 \times 10^{5}-1.0 \times$ $10^{6} / \mathrm{mL}$. Then, $100 \mu \mathrm{L}$ of cell suspension was added into a 96well plate, and $100 \mu \mathrm{L}$ of the samples was added. $20 \mu \mathrm{g} \mathrm{mL}^{-1}$ ConA was added to the stimulation group, and the same amount of RPMI 1640 was used as a blank control, and then the cells were incubated at $37^{\circ} \mathrm{C}$ for $48 \mathrm{~h}$ in an incubator with $5 \%$ $\mathrm{CO}_{2}$. CCK8 $(10 \mu \mathrm{L})$ solution was added, and incubated under the same conditions for 2-4 h, and the absorbance at $450 \mathrm{~nm}$ was read on a microplate reader (Multiskan FC, Thermo Fisher Scientific, The United States).

\subsection{Assessment of phagocytosis, and NO, TNF- $\alpha$ and IL-6 production}

Raw 264.7 murine macrophage cells were cultured in DMEM medium supplemented with $10 \%$ fetal bovine serum, 100 units per $\mathrm{mL}$ of penicillin, and 100 units per $\mathrm{mL}$ of streptomycin in a humidified $5 \% \mathrm{CO}_{2}$ atmosphere at $37{ }^{\circ} \mathrm{C}$. Cell concentration was adjusted to $3.0 \times 10^{5}-1.0 \times 10^{6} / \mathrm{mL}$ in order to make the cell survival rate higher than 95\%. DMEM $(100 \mu \mathrm{L})$ was added to a 96-well plate, and $100 \mu \mathrm{L}$ of the samples at the concentration of 6.25-400 $\mu \mathrm{g} \mathrm{mL}^{-1}$ was added after removing the supernatant. LPS $\left(1 \mu \mathrm{g} \mathrm{mL}{ }^{-1}\right)$ was added to the stimulation group, and then incubated at $37{ }^{\circ} \mathrm{C}$ for $48 \mathrm{~h}$ in an incubator with $5 \% \mathrm{CO}_{2}$. The sample $(100 \mu \mathrm{L})$ was replaced with DMEM as a blank control. After incubation for $48 \mathrm{~h}$, the blank group, sample group and LPS group were subjected to the following procedures for the purpose of determining the proliferation rate of macrophages, phagocytosis ability, and NO, TNF- $\alpha$, and IL- 6 production.

(1) After completing the procedures described above, the method of assessing the proliferation rate of macrophages is as follows: $20 \mu \mathrm{L}$ MTT solution $\left(5 \mathrm{mg} \mathrm{mL}^{-1}\right.$ ) was added, and incubated for 4 hours after sufficient shaking; then the supernatant was removed, $100 \mu \mathrm{L}$ DMSO was subsequently added and the samples were kept $10 \mathrm{~min}$ for colorizing purposes; the absorbance was finally read at the wavelength of $490 \mathrm{~nm}$.

(2) In order to determine the phagocytosis, $20 \mu \mathrm{L}$ of $0.1 \%$ neutral red solution was added, and was further incubated for 2-4 h. The supernatant was removed, and washed with PBS buffer twice. Then, $100 \mu \mathrm{L}$ of cytolysate was collected and transferred onto a 96-well plate. The 96-well plate was then vibrated by a shaker for $10 \mathrm{~min}$ at room temperature, and the absorbance at $540 \mathrm{~nm}$ was read on a microplate reader.

(3) In order to determine the content of NO, the supernatant was collected, and the NO content was assessed by Griess Reagent System G2930 (Promega Corporation, Wisconsin, USA) according to the manual.

(4) The supernatant was collected in order to determine the content of TNF- $\alpha$, and the production of TNF- $\alpha$ was calculated according to the manual of the ELISA kit (Mouse TNF- $\alpha$, ExCell Bio, China).

(5) Likewise, the IL-6 production was assessed and calculated based on the procedures described on the manual of the ELISA kit (Mouse IL-6, ExCell Bio, China).

\subsection{Peptide synthesis}

The peptides identified by LC-MS/MS were synthesized by solid phase peptide synthesis (China Peptides Co., Ltd.). The purity of the synthesized peptides was analyzed by HPLC. The synthesized peptides were also subjected to ESI-MS for MS analysis.

\subsection{Statistical analysis}

All the tests were repeated in triplicate, except for the immunoregulatory activity tests of the F31 fraction, which were repeated two times. Data were evaluated using SPSS 17.0 software (SPSS Inc, USA). Data were expressed as the mean \pm standard deviation (SD). The mean values were analyzed using one-way analysis of variance (ANOVA). The significant differences were determined with a $95 \%$ confidence interval $(p<0.01)$ with the exception of the TNF- $\alpha$ assessment of the synthesized peptides, in which a significant difference was defined as $p<0.05$.

\section{Results and discussion}

3.1 Degree of hydrolysis of the hydrolysate, and amino acid profile and molecular weight distribution of OHLM and its proliferative activity

An enzymatic technique was used to produce oyster peptides, and it is important to determine the $\mathrm{DH}$ of the hydrolysate, 
since the properties and biological functions of a hydrolysate are closely related to the $\mathrm{DH}^{\mathbf{2 0 , 2 1}}$ Therefore, it is crucial to determine the $\mathrm{DH}$ of the oyster hydrolysate, and make our work reproducible. The $\mathrm{DH}$ of the oyster hydrolysate is calculated as $27.97 \% \pm 1.27$ by using the formula described above.

The oyster hydrolysate then went through a series of filtering processes to get rid of impurity substances and other molecules with large molecular weight, after which OHLM was obtained. As shown in Table 1, the amino acid characteristics of the OHLM were analyzed. The ratio of essential amino acids to nonessential amino acids was 57.76, which means that there were more essential amino acids in the OHLM sample. The most abundant amino acid in the sample is clearly glutamate $(8.24 \mathrm{~g} / 100 \mathrm{~g})$, which might contribute to modulating the immune system after being consumed. This is mainly because glutamate, as an excitatory neurotransmitter and substrate of forming $\gamma$-aminobutyrate (GABA), plays a critical role in the nervous system and lymphocytes and macrophages. ${ }^{22} \mathrm{~A}$ recent review has been published in which the authors concluded that peptides with immunomodulating effects usually consist of hydrophobic amino acids. ${ }^{19}$ As calculated, the OHLM sample has $40.34 \%$ hydrophobic amino acids and it shows good hydrophobic activity in nature.

As shown in Table 2, the molecular weight of $71.55 \%$ of the peptides in the OHLM was less than $2.5 \mathrm{kDa}$, that of $7.86 \%$ of the peptides in the OHLM was $2.5-5 \mathrm{kDa}$, and that of the other $20.59 \%$ of peptides in the OHLM were more than $10 \mathrm{kDa}$. Protein digestion goes through 3 stages after consumption by the human body, which is gastric breakdown, pancreatic breakdown, and finally absorption in the intestines. ${ }^{23}$ The proteins are absorbed either in the form of free amino acids or the form of oligopeptides, which facilitates their bioavailability. ${ }^{23,24}$ Therefore, the OHLM containing $79.41 \%$ peptides

Table 1 The amino acid profile of OHLM

\begin{tabular}{lc}
\hline Amino acid & Quantity in OHLM (g/100 g) \\
\hline Asp & 4.40 \\
Thr & 1.89 \\
Ser & 1.69 \\
$\mathrm{Glu}^{a}$ & 8.24 \\
$\mathrm{Gly}^{a}$ & 3.05 \\
$\mathrm{Ala}^{a}$ & 2.94 \\
$\mathrm{Val}^{a}$ & 2.11 \\
$\mathrm{Met}^{\mathrm{Ile}}$ & 1.14 \\
Leu $^{a}$ & 2.07 \\
Tyr & \\
$\mathrm{Phe}^{a}$ & 2.98 \\
$\mathrm{His}^{a}$ & 0.28 \\
Lys & 1.49 \\
Arg & 0.81 \\
Pro & \\
The percentage of hydrophobic & 3.28 \\
amino acids (\%) & 2.63 \\
Ratio of essential amino acids & 1.83 \\
to nonessential amino acids (\%) & 40.34 \\
${ }^{a}$ Indicates hydrophobic amino acids. &
\end{tabular}

Table 2 Molecular distribution of OHLM

\begin{tabular}{lllll}
\hline Molecular weight & $<2.5 \mathrm{kDa}$ & $2.5-5 \mathrm{kDa}$ & $5-10 \mathrm{kDa}$ & $>10 \mathrm{kDa}$ \\
Percentage (\%) & 71.55 & 7.86 & N/A & 20.59 \\
\hline
\end{tabular}

with lower molecular weight $(<5 \mathrm{kDa})$ will have a high bioavailability, and thus have great potential for affecting physiological activities in the human body.

We further examined the proliferation rate of spleen lymphocytes in vitro. As shown in Fig. 1, the proliferation rate of all groups was significantly higher than that of the group treated with ConA at a concentration of $10 \mu \mathrm{g} \mathrm{mL}{ }^{-1}$. The results suggested that the OHLM increased the number of lymphocytes and exhibited an immunoregulatory effect on the spleen lymphocytes.

Considering that the ingredients in the OHLM sample are relatively complex, the actual bioactive components responsible for its immunoregulatory effects could not be determined. Therefore, anion exchange chromatography and RP-HPLC were applied sequentially to obtain oyster peptides.

\subsection{Peptide separation by anion exchange chromatography}

The principles of anion exchange chromatography are that proteins above their isoelectric point are normally negatively charged, and can be combined with the stationary matrix, and when the unwanted components are washed away completely, the target proteins can be collected by adding eluent. ${ }^{25}$ Here, Capto Q, a strong anion exchanger with rapid and effective separation ability, was applied to bind the peptides extracted from oysters, and then the isolated oyster peptides were washed with sodium chloride solution. We collected 6 fractions, named as F1-F6 (Fig. 2a). The proliferation rate assay was applied for the 6 fractions, and Fig. 2b shows that F3 exhibited the best effect on promoting the growth of spleen cells compared with the other groups. Therefore, we chose the F3 fraction for further purification.

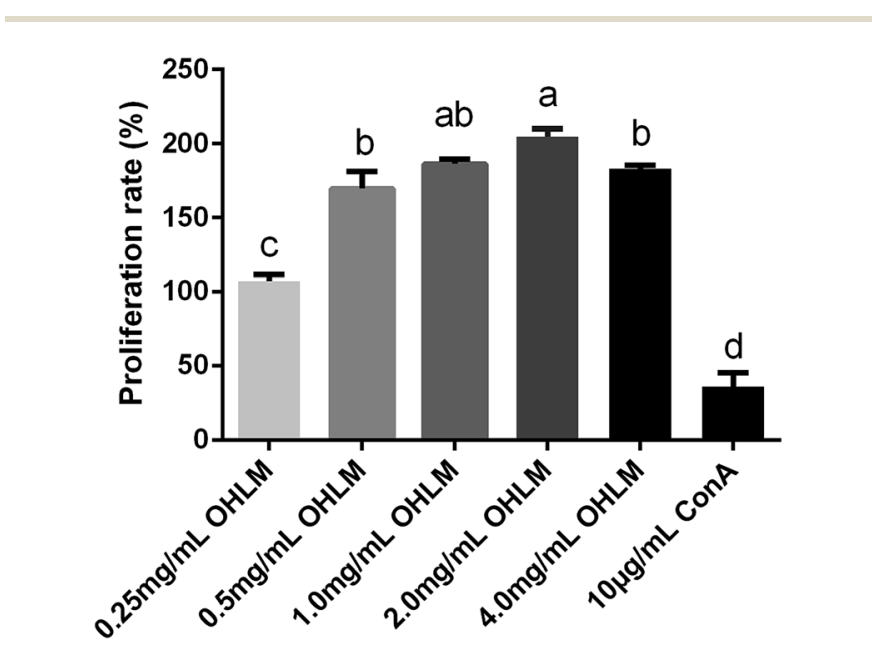

Fig. 1 Evaluation of the proliferation rate of OHLM. All data are expressed as mean \pm SD. Different letters indicate significant differences between groups ( $p<0.01$ ). 

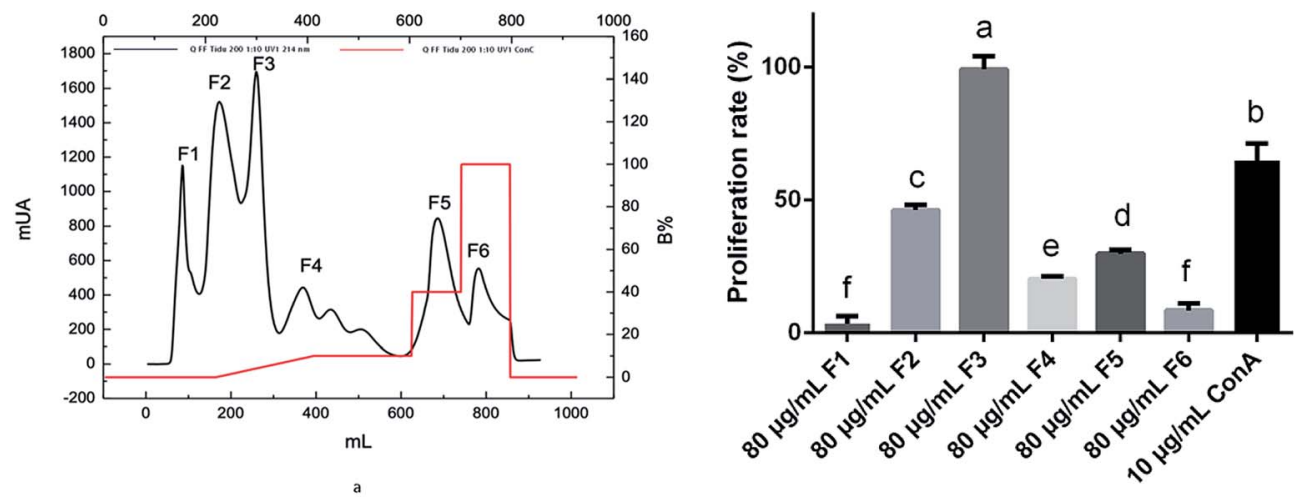

b

Fig. 2 Elution curve of the fractions separated in anion exchange chromatography and their effect on the proliferation rate of lymphocytes. The elution curve of the peptide fractions is shown in (a). Six fractions (F1, F2, F3, F4, F5 and F6) were obtained via anion exchange chromatography, and their effects on the proliferation rates of spleen cells are shown in (b). All data are expressed as mean \pm SD. Different letters indicate significant differences between groups $(p<0.01)$.

\subsection{Peptide purification by RP-HPLC}

RP-HPLC is an excellent technique for analyzing peptides and proteins, and the advantages are as follows: high resolution, which can distinguish two very closely related molecules, controllable mobile phase, high productivity and high reproducibility. ${ }^{26}$ The fraction, F3, with the highest proliferative activity was subsequently fractioned by RP-HPLC. Three fractions were collected (Fig. 3a), and their proliferative activity is shown in Fig. 3b. The proliferation rate of the F31 fraction is 44 $\pm 7 \%$, which is the highest among the three fractions. Therefore, the biological activities and sequences of peptides in F31 were further analyzed.

\subsection{Immunoregulatory activities of the F31 fraction}

Proliferation of spleen lymphocytes plays a pivotal role in defending against foreign materials, and reducing the number of lymphocytes would make the immune system vulnerable to foreign infectious organisms. ${ }^{27}$ The proliferative ability of the
F31 fraction is shown in Fig. 4a. The results suggested that the F31 fraction had no cytotoxic effect on the lymphocytes and exhibited a proliferative effect on spleen lymphocytes in a dosedependent manner. When the concentration of the F31 fraction reached to $50 \mu \mathrm{g} \mathrm{mL}^{-1}$, the proliferation rate showed the greatest intensity $(151 \pm 10 \%)$. Another two immunoregulatory peptides purified from other sources were reported to have a best proliferation rate of only less than $60 \% .^{28,29}$ This suggested that the purified $\mathrm{F} 31$ fraction had a potent proliferative effect on spleen lymphocytes.

Phagocytosis by macrophages is another important aspect to show if a peptide has immunoregulatory activity. Phagocytes, which are capable of controlling the uptake and degradation of foreign materials, are believed to be an important participator in the immune response. ${ }^{30}$ In this experiment, we used neutral red as a foreign material to stimulate mouse macrophages, and the results are shown in Table 3. All the groups treated with the F31 faction showed significantly better effects than the LPS group, and the best phagocytosis effect exerted by the F31
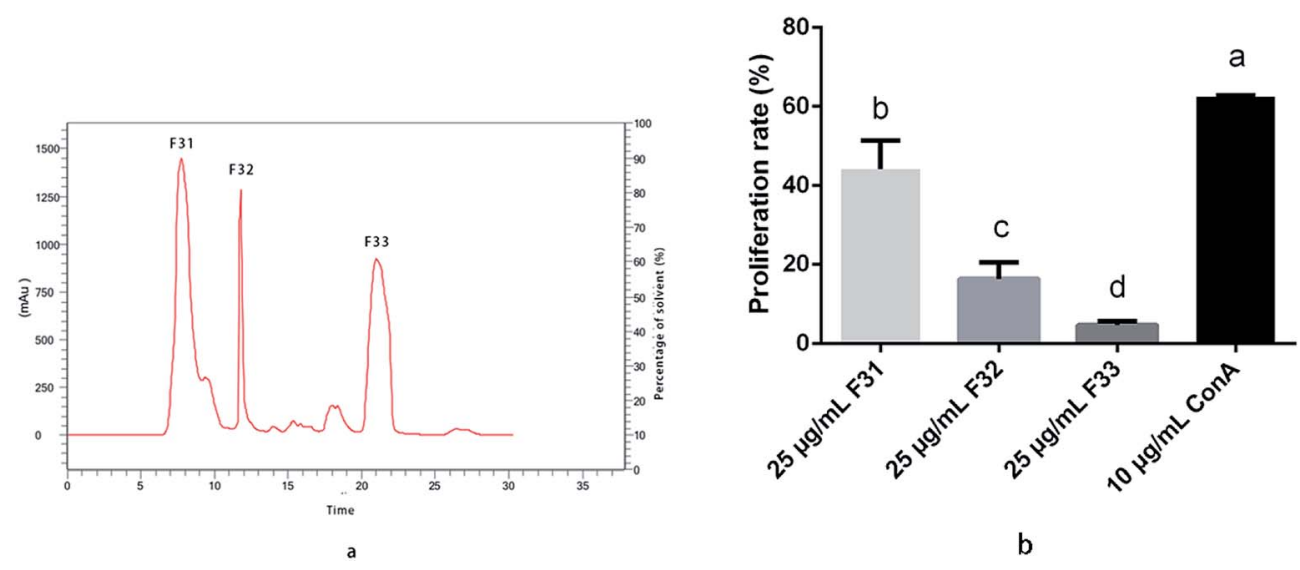

Fig. 3 Elution curve of the fractions separated in RP-HPLC and their effect on the proliferation rate of lymphocytes. The elution curve is shown in (a), and F31, F32 and F33 were obtained using RP-HPLC. The proliferation rates with F31, F32 and F33 are shown in (b). All data are expressed as mean \pm SD. Different letters indicate significant differences between groups $(p<0.01)$. 


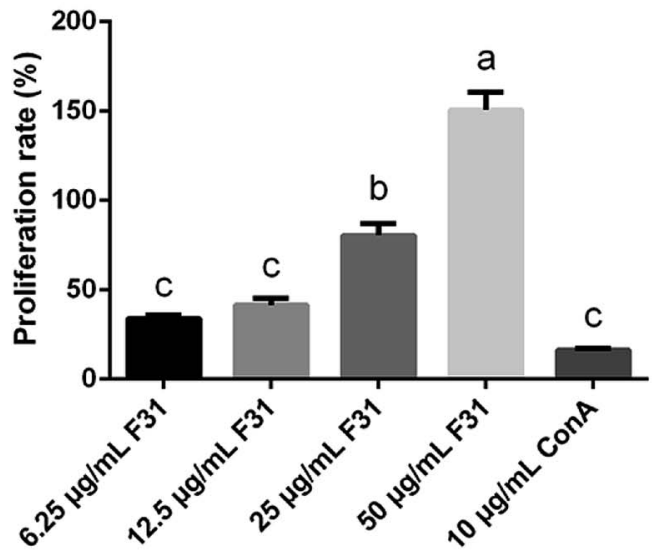

a
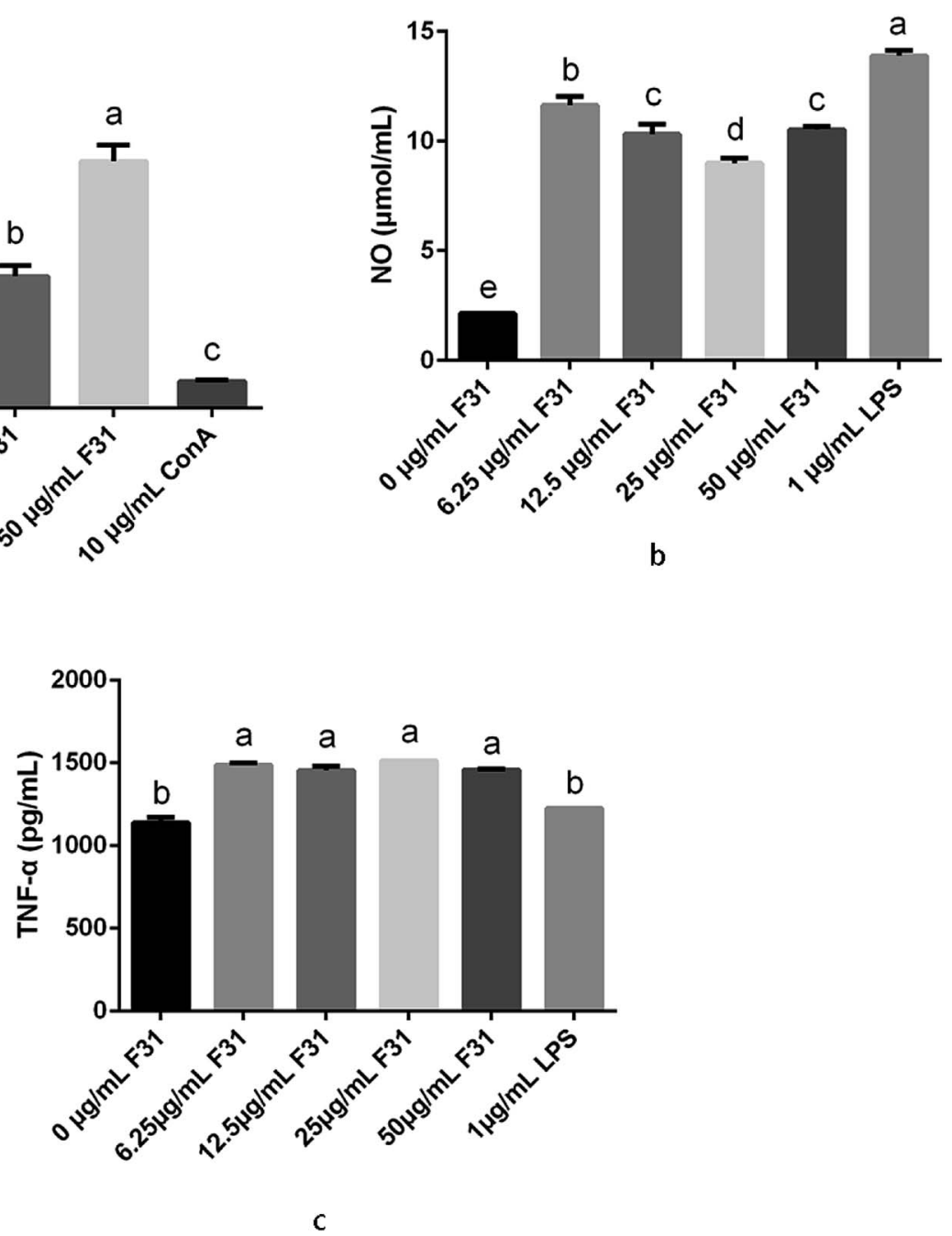

Fig. 4 Evaluation of the immunoregulatory activity of the F31 fraction in vitro. (a) Shows the proliferation rates of spleen lymphocytes; (b) shows the NO production synthesized by spleen macrophages; (c) shows the production of TNF- $\alpha$ by macrophages. All data are expressed as mean \pm SD. Different letters indicate significant differences between groups $(p<0.01)$.

fraction was $230 \%$ at a dose of $50 \mu \mathrm{g} \mathrm{mL}^{-1}$. Fang et al. (2017) reported that the highest phagocytosis rate of hydrolysates from rice proteins was less than $70 \%$ at the concentration of $50 \mu \mathrm{g}$ $\mathrm{mL}^{-1}{ }^{31}$ These results suggested that $\mathrm{F} 31$ has a strong ability to enhance the phagocytosis of macrophages.

The ability of stimulating NO production after treatment with the F31 fraction was determined, and the results are shown in Fig. 4b. It is known that NO is involved in vasodilation, platelet aggregation, neuronal signal transduction and inflammation. ${ }^{32}$ An appropriate amount of NO produced by iNOS can neutralize infectious pathogens, but excessive amounts of NO production would compromise the normal function of immunity and lead to cell death. ${ }^{32-34}$ As shown in Fig. 4c, the NO production of all the groups treated with the F31 fraction was significantly lower compared to the LPS group, but significantly higher than the blank control group. Since the F31 fraction had no cytotoxic effects on the macrophage cells (Fig. 4a), this indicated that the F31 fraction stimulated the macrophage cells to synthesize NO, and the quantity of NO synthesized by the F31 fraction was significantly lower than the harmful quantity induced by LPS. It has been reported that various peptides have the ability to stimulate NO production, which can further regulate relevant pathways of physiological activities, including increasing the concentration of $\mathrm{Ca}^{2+}$ in endothelial cells, acting

Table 3 Effects of the F31 fraction on the phagocytosis activity of macrophages $^{a}$

\begin{tabular}{llll}
\hline Group & Dose & Absorbance & $\begin{array}{l}\text { Macrophage } \\
\text { phagocytosis (\%) }\end{array}$ \\
\hline Control & - & $0.75 \pm 0.01 \mathrm{~d}$ & 100.0 \\
F31 & $6.25 \mu \mathrm{g} \mathrm{mL}^{-1}$ & $0.87 \pm 0.09 \mathrm{~cd}$ & 116.3 \\
& $12.5 \mu \mathrm{g} \mathrm{mL}^{-1}$ & $1.0 \pm 0.1 \mathrm{c}$ & 136.2 \\
& $25 \mu \mathrm{g} \mathrm{mL}^{-1}$ & $1.44 \pm 0.05 \mathrm{~b}$ & 196.0 \\
LPS & $50 \mu \mathrm{g} \mathrm{mL}^{-1}$ & $1.71 \pm 0.04 \mathrm{a}$ & 230.0 \\
& $1 \mu \mathrm{g} \mathrm{mL}^{-1}$ & $0.46 \pm 0.03 \mathrm{e}$ & 62.2
\end{tabular}

${ }^{a}$ All data are expressed as mean \pm SD. Means within a row with different letters indicate significant differences $(p<0.01)$. 


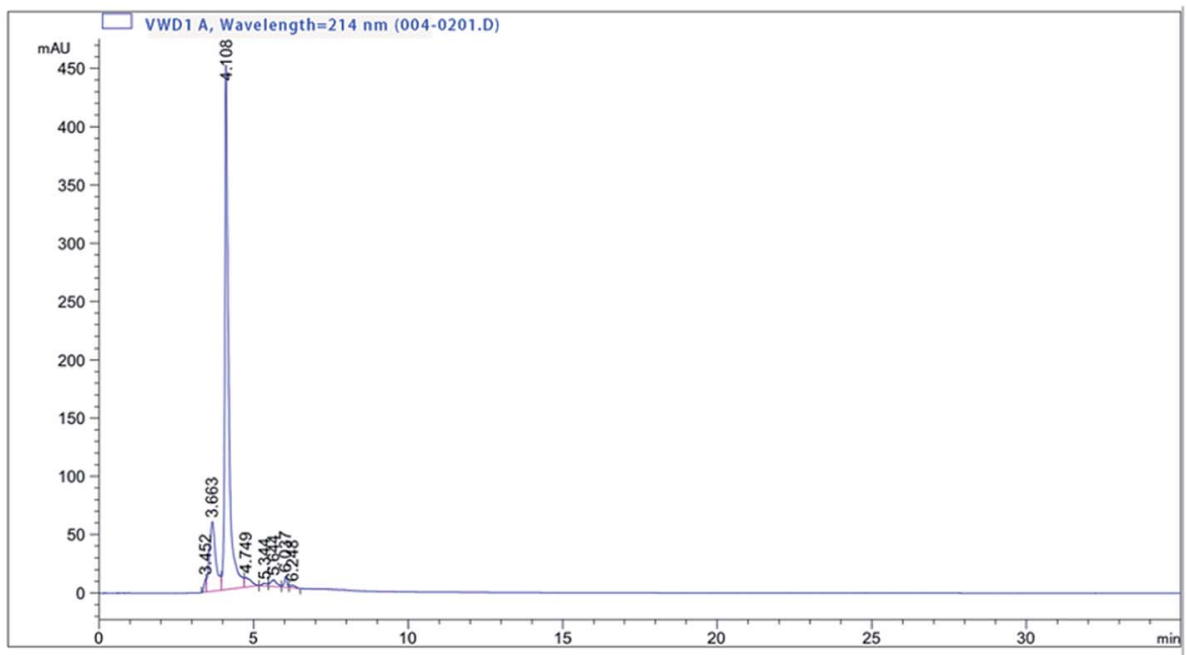

a
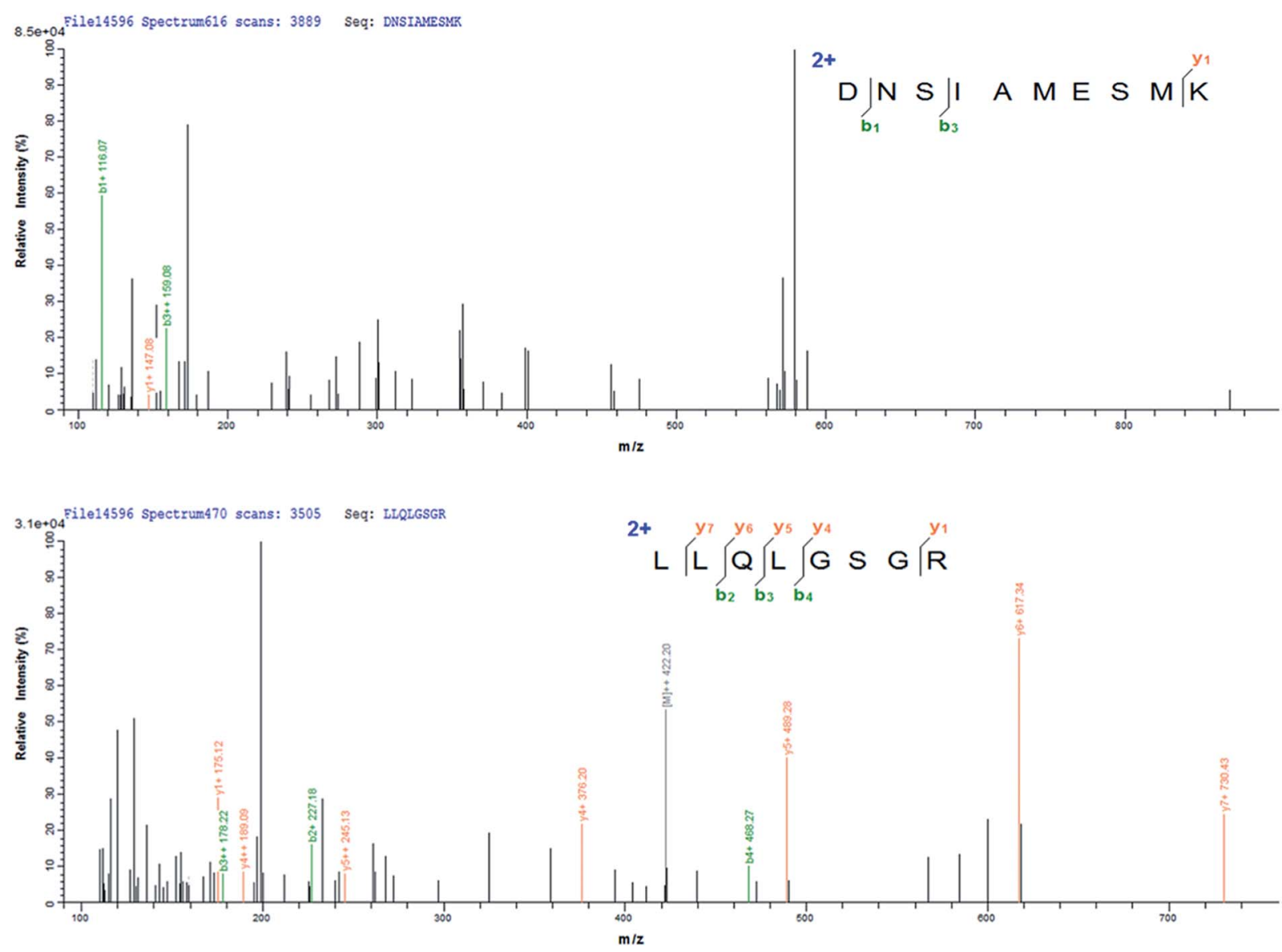

b

Fig. 5 Peptide identification from the F31 fraction via LC-MS/MS. (a) shows the RP-HPLC chromatogram of the F31 fraction before identification by MS/MS. Two peptides, LLQLGSGR and DNSIAMESMK, were identified from the F31 fraction (b).

as a physiological messenger, and inhibiting the growth of tumor cells and increasing antimicrobial activity. ${ }^{35-37}$ Taken together, the increased NO of the F31 fraction played an important role in immunoregulation.
The production of TNF- $\alpha$ was also examined in our study, and the results are shown in Fig. 4c. When immune cells, for instance macrophages, encounter an attack by foreign pathogens, cytokines like TNF- $\alpha$ are produced to initiate an 


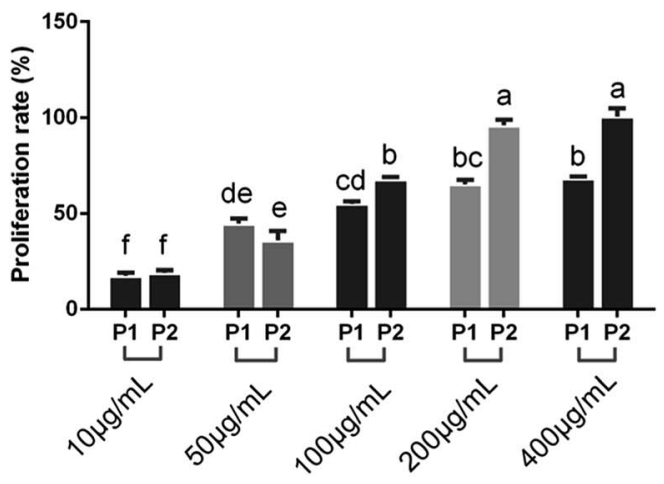

a

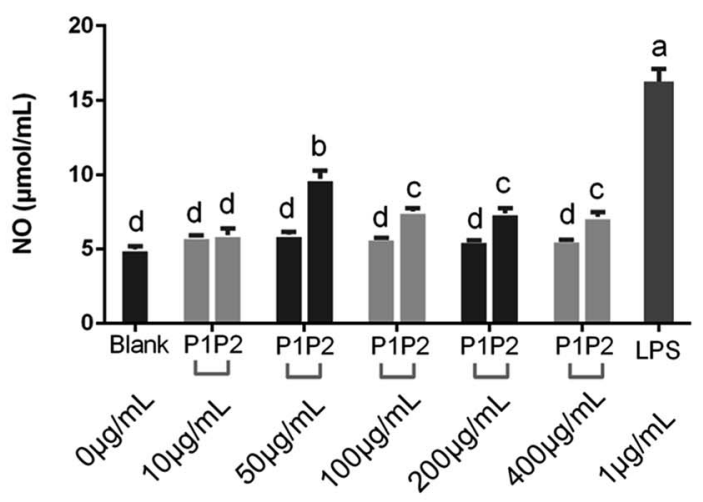

b

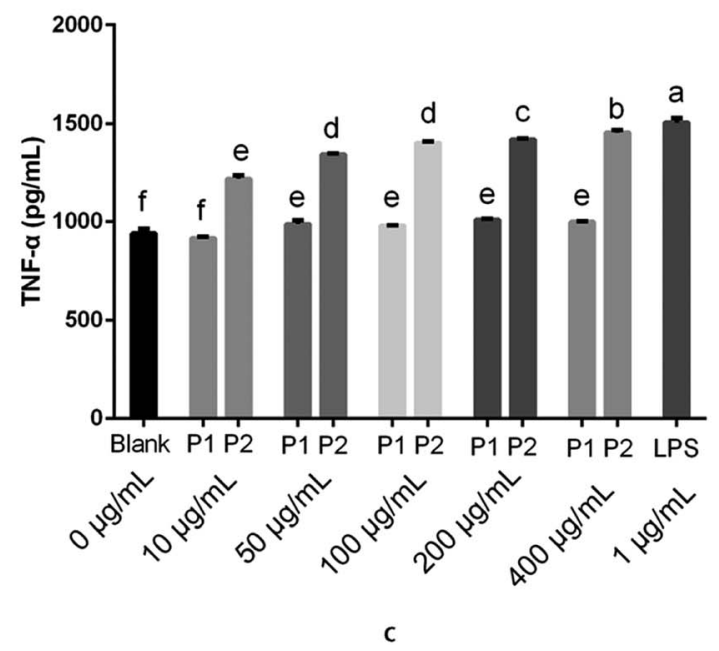

Fig. 6 Proliferation rate, and NO and TNF- $\alpha$ production of the synthesized peptides. (a) Shows the proliferation rate after treatment by the synthesized peptides, P1 and P2 ( $p<0.01$ ); (b) shows the NO production after treatment by the synthesized peptides $(p<0.05)$; (c) shows the TNF- $\alpha$ production induced by the synthesized peptides $(p<0.01)$. All data are expressed as mean \pm SD. Different letters indicate significant differences between groups $(p<0.01, p<0.05)$.

inflammatory reaction in order to maintain immune function. ${ }^{38}$ Compared to the LPS group, all the groups treated by the F31 fraction significantly promoted the production of TNF- $\alpha$. Similar results were observed in other studies. For example, peptides purified from Wheat Germ Globulin significantly induced the production of TNF- $\alpha$, which is also higher than in the LPS group. ${ }^{39}$ Wang et al. (2015) reported that bioactive polysaccharides showed strong activity to produce TNF- $\alpha$, and the production of TNF- $\alpha$ can enhance the immune functions of the body. ${ }^{40}$

Taken together, the fact that the F31 fraction exhibited potent immunoregulatory effects in multiple assays made this fraction an excellent source for identifying immunoregulatory peptides.

\subsection{Peptide identification by LC-MS/MS}

For identifying the sequence of peptides, the F31 faction was further purified and identified by LC-MS/MS. Two peptides with higher confidence levels (>95\%) were identified in the F31 faction, and the HPLC chromatograms and the MS/MS spectra of these two peptides are shown in Fig. 5. These two peptides were identified as DNSIAMESMK (P1) and LLQLGSGR (P2); both of them are cationic peptides with two positive charges, and their theoretical molecular masses are 842.4964 Da and $1156.4702 \mathrm{Da}$, respectively. Generally, shorter peptides (2-10 residues) with a high percentage of hydrophobic amino acids are believed to have better biological activity in terms of modulating the immune system. ${ }^{19} \mathrm{P} 2$ found in F31 has $62.5 \%$ hydrophobic amino acids, which indicates that P2 might be a more potent candidate for immune modulation than P1.

\subsection{Validation of the immunoregulatory activities of the two peptides}

By utilizing the LC-MS/MS technique, the two potential peptides, DNSIAMESMK (P1) and LLQLGSGR (P2), were identified from the F31 fraction from oyster hydrolysate. In order to further study their immunoregulatory activities, the two peptides were chemically synthesized by solid phase synthesis, and the purity of P1 and P2 was calculated to be $98.91 \%$ and $99.37 \%$, respectively. 
Table 4 Effects of the synthesized peptides on the phagocytosis activity of macrophages ${ }^{a}$

\begin{tabular}{llcl}
\hline Group & Dose & Absorbance & $\begin{array}{l}\text { Macrophage } \\
\text { phagocytosis (\%) }\end{array}$ \\
\hline Control & - & $0.255 \pm 0.003 \mathrm{~g}$ & 100.0 \\
P1 & $10 \mu \mathrm{g} \mathrm{mL}^{-1}$ & $0.302 \pm 0.006 \mathrm{f}$ & 118.3 \\
& $50 \mu \mathrm{g} \mathrm{mL}^{-1}$ & $0.39 \pm 0.01 \mathrm{~cd}$ & 152.7 \\
& $100 \mu \mathrm{g} \mathrm{mL}^{-1}$ & $0.407 \pm 0.009 \mathrm{bc}$ & 159.7 \\
& $200 \mu \mathrm{g} \mathrm{mL}^{-1}$ & $0.39 \pm 0.01 \mathrm{~cd}$ & 154.0 \\
P2 & $400 \mu \mathrm{g} \mathrm{mL}^{-1}$ & $0.426 \pm 0.009 \mathrm{~b}$ & 167.0 \\
& $10 \mu \mathrm{g} \mathrm{mL}^{-1}$ & $0.273 \pm 0.006 \mathrm{~g}$ & 107.1 \\
& $50 \mu \mathrm{g} \mathrm{mL}^{-1}$ & $0.353 \pm 0.008 \mathrm{e}$ & 138.2 \\
& $100 \mu \mathrm{g} \mathrm{mL}^{-1}$ & $0.37 \pm 0.02 \mathrm{de}$ & 143.9 \\
& $200 \mu \mathrm{g} \mathrm{mL}^{-1}$ & $0.434 \pm 0.005 \mathrm{~b}$ & 170.2 \\
LPS & $400 \mu \mathrm{g} \mathrm{mL}^{-1}$ & $0.464 \pm 0.005 \mathrm{a}$ & 181.9 \\
a All data are expressed as mean \pm SD. Means within a row with \\
different letters indicate significant differences $(p<0.01)$.
\end{tabular}

Validation of their immunoregulatory activities was subsequently achieved through a series of assessments of critical factors, including the proliferation rate of macrophages, TNF$\alpha$ production, NO production, IL-6 production, and phagocytosis ability, and the results are presented in Fig. 6, Table 4 and 5. In general, both peptides were capable of increasing the proliferation rate, NO and TNF- $\alpha$ effectively, of which P2 had significantly better effects than P1. It was relatively more complex for their phagocytosis ability, in which P1 gave a significantly higher phagocytosis rate than P2 when their doses were under $200 \mu \mathrm{g} \mathrm{mL} \mathrm{m}^{-1}$. However, $\mathrm{P} 2$ presented a better phagocytosis ability than $\mathrm{P} 1$ when the doses were higher than $200 \mu \mathrm{g} \mathrm{mL}^{-1}$. IL-6 is believed to be an important cytokine in regulating the immune response. ${ }^{41}$ As shown in Table 5, P2 obviously produced more IL-6 than P1 without compromising the normal functions of cells. We can conclude that the synthesized peptide P2 had better immunoregulatory activities than $\mathrm{P} 1$, and this is consistent with the characteristics of each peptide, where the content of hydrophobic amino acids in P2 was much higher than that in P1.

Table 5 Effects of the synthesized peptides on IL- 6 production ${ }^{a}$

\begin{tabular}{lll}
\hline Group & Dose & Quantity $\left(\mathrm{pg} \mathrm{mL} \mathrm{mL}^{-1}\right)$ \\
\hline \multirow{2}{*}{ Control } & - & $165 \pm 4 \mathrm{~h}$ \\
P1 & $10 \mu \mathrm{g} \mathrm{mL}^{-1}$ & $230 \pm 7 \mathrm{gh}$ \\
& $50 \mu \mathrm{gL}^{-1}$ & $317 \pm 6 \mathrm{gh}$ \\
& $100 \mu \mathrm{g} \mathrm{mL}^{-1}$ & $371 \pm 2 \mathrm{gh}$ \\
& $200 \mu \mathrm{g} \mathrm{mL}^{-1}$ & $395 \pm 21 \mathrm{fg}$ \\
& $400 \mu \mathrm{g} \mathrm{mL}^{-1}$ & $5158 \mathrm{f}$ \\
P2 & $10 \mu \mathrm{mL}^{-1}$ & $366 \pm 13 \mathrm{gh}$ \\
& $50 \mu \mathrm{gmL}^{-1}$ & $812 \pm 9 \mathrm{e}$ \\
& $100 \mu \mathrm{g} \mathrm{mL}^{-1}$ & $1349 \pm 77 \mathrm{c}$ \\
& $200 \mu \mathrm{g} \mathrm{mL}^{-1}$ & $1668 \pm 20 \mathrm{c}$ \\
& $400 \mu \mathrm{g} \mathrm{mL}^{-1}$ & $2050 \pm 82 \mathrm{~b}$ \\
LPS & $1 \mu \mathrm{gL}^{-1}$ & $23496 \pm 265 \mathrm{a}$
\end{tabular}

${ }^{a}$ All data are expressed as mean \pm SD. Means within a row with different letters indicate significant differences $(p<0.01)$.

\section{Conclusions}

In this study, we isolated and purified two peptides from oyster hydrolysate with immunoregulatory activities, and the sequences were identified as DNSIAMESMK (P1) and LLQLGSGR (P2). The two peptides were then chemically synthesized, and their immunoregulatory activities were verified by testing their proliferation rate, NO production, TNF$\alpha$ production, IL-6 production, and phagocytosis abilities. The results showed that both P1 and P2 significantly promoted the proliferation rate of macrophages and their phagocytosis abilities, and induced the production of NO, TNF- $\alpha$ and IL-6. However, P2, with more hydrophobic amino acids, was more potent than P1. In a further study, we would like to investigate the structure-activity relationship and unravel the potential mechanisms of these peptides in regulating immunity.

\section{Ethics statement}

All animal experiments were performed in strict accordance with the NIH guidelines for the care and use of laboratory animals (NIH Publication No. 85-23 Rev. 1985), and approved by the Welfare Committee of the Centre of Experimental Animals at the College of Food Science and Technology of Guangdong Ocean University (Zhanjiang, China).

\section{Conflicts of interest}

None.

\section{Abbreviations}

RP-HPLC Reverse phase high-performance liquid chromatography

HPLC High-performance liquid chromatography

RPMI Roswell Park Memorial Institute

DMEM Dulbecco's modified Eagle medium

LPS Lipopolysaccharide

ConA Concanavalin A

ABTS 2,2'-Azino-bis(3-ethylbenzothiazoline-6-sulfonic acid)

OHLM Oyster hydrolysates with low molecular weight

Tris-HCl Tris(hydroxymethyl)aminomethane

LC-MS/ Liquid chromatograph-mass spectrometer

MS

PBS Phosphate buffered solution

CCK8 Cell counting kit-8

EDTA Ethylenediaminetetraacetic acid

DH Degree of hydrolysis

\section{Acknowledgements}

This work was supported by the Applied Science and Technology Research and Development Project of Guangdong Province (2016B020235002), the Modern Agro-industry Technology Research System of China (CARS-49), the Guangdong 
Higher Education Institution Innovative Team of High Value Processing and Utilization of Aquatic Products (GDOU2016030503) and the Industrial Development Special Fund Project of Dapeng New District, Shenzhen, China (KY20180111). We gratefully acknowledge and are indebted to the anonymous referees for their comments and constructive suggestions provided for improving the manuscript.

\section{References}

1 S. Lordan, R. P. Ross and C. Stanton, Mar. Drugs, 2011, 9, 1056-1100.

2 P. A. Harnedy and R. J. FitzGerald, J. Funct. Foods, 2012, 4, 624.

3 J. Wijsman, K. Troost, J. Fang and A. Roncarati, in Goods and Services of Marine Bivalves, Springer, 2019, pp. 7-26.

4 Z. Zhang, G. Su, F. Zhou, L. Lin, X. Liu and M. Zhao, Food Res. Int., 2019, 120, 178-187.

5 H. Fuda, M. Watanabe, S.-P. Hui, S. Joko, H. Okabe, S. Jin, S. Takeda, E. Miki, T. Watanabe and H. Chiba, Food Chem., 2015, 176, 226-233.

6 K. Asha, K. R. Kumari, K. A. Kumar, N. S. Chatterjee, R. Anandan and S. Mathew, Int. J. Pept. Res. Ther., 2016, 22, 421-433.

7 L. Zhang, Y. Liu, X. Tian and Z. Tian, J. Food Process. Preserv., 2015, 39, 404-412.

8 S. Umayaparvathi, S. Meenakshi, V. Vimalraj, M. Arumugam, G. Sivagami and T. J. B. Balasubramanian, Biomed. Prev. Nutr., 2014, 4, 343-353.

9 T. Wang, J. Ding, H. Li, J. Xiang, P. Wen, Q. Zhang, L. Yin, W. Jiang and C. Shen, Int. J. Biol. Macromol., 2016, 83, 195197.

10 B.-H. Nam, J.-K. Seo, M. J. Lee, Y.-O. Kim, D.-G. Kim, C. M. An and N. G. Park, Fish Shellfish Immunol., 2015, 45, 167-174.

11 T.-G. Lee and S. Maruyama, Biochem. Biophys. Res. Commun., 1998, 253, 604-608.

12 G. Hao, C. Zhang, W. Cao and J. Hao, Pharm. Biol., 2014, 52, 723-728.

13 E.-K. Kim, Y.-S. Kim, S.-J. Lee, Y.-J. Jeon, J. D. Lee, T.-I. Son, C.-B. Ahn, Y.-T. Kim, S.-H. Moon and B.-T. Jeon, Food Sci. Biotechnol., 2010, 19, 213-217.

14 B. Cai, H. Chen, H. Sun, P. Wan, H. Sun and J. Pan, Food Funct., 2016, 7, 390-397.

15 Y.-K. Wang, H.-L. He, G.-F. Wang, H. Wu, B.-C. Zhou, X.-L. Chen and Y.-Z. Zhang, Mar. Drugs, 2010, 8, 255-268.

16 J.-Y. Cheng, L.-T. Ng, C.-L. Lin and T.-R. Jan, Immunopharmacol. Immunotoxicol., 2013, 35, 235-240.

17 D. Xu, F. Lin, X. Zhu, W. Liu, X. Chen, J. Feng, A. Fan, M. Cai and Y. Xu, J. Peking Univ., Health Sci., 2016, 48, 392-397.
18 K. K. Asha, R. Anandan, S. Mathew and P. T. Lakshmanan, Egypt. J. Aquat. Res., 2014, 40, 35-41.

19 M. Chalamaiah, W. Yu and J. Wu, Food Chem., 2018, 245, 205-222.

20 Q. Liu, B.-H. Kong, Y.-L. L. Xiong and X.-F. Xia, Food Chem., 2010, 118, 403-410.

21 S. N. Jamdar, V. Rajalakshmi, M. D. Pednekar, F. Juan, V. Yardi and A. Sharma, Food Chem., 2010, 121, 178-184.

22 P. Li, Y.-L. Yin, D. Li, S. W. Kim and G. Wu, Br. J. Nutr., 2007, 98, 237-252.

23 D. Matthews, J. Clin. Pathol., 1971, 5, 29.

24 T. Matsui, J. Agric. Food Chem., 2018, 66, 393-394.

25 P. M. Cummins, O. Dowling and B. F. O'Connor, in Protein Chromatography, Springer, 2011, pp. 215-228.

26 M.-I. Aguilar, in HPLC of Peptides and Proteins, Springer, 2004, pp. 9-22.

27 R. J. North, Cell. Immunol., 1973, 7, 166-176.

28 X. Q. He, W. H. Cao, G. K. Pan, L. Yang and C. H. Zhang, J. Sci. Food Agric., 2015, 95, 1544-1553.

29 H. Hou, Y. Fan, B. Li, C. Xue, G. Yu, Z. Zhang and X. Zhao, Food Chem., 2012, 134, 821-828.

30 A. Aderem and D. M. Underhill, Annu. Rev. Immunol., 1999, 17, 593-623.

31 Y. Fang, X. Chen, P. Luo, F. Pei, B. M. Kimatu, K. Liu, M. Du, W. Qiu and Q. Hu, J. Food Sci., 2017, 82, 515-522.

32 H. Y. Min, S. H. Song, B. Lee, S. Kim and S. K. Lee, Chem. Biodiversity, 2010, 7, 409-414.

33 C. Bogdan, Nat. Immunol., 2001, 2, 907.

34 T. Joo, K. Sowndhararajan, S. Hong, J. Lee, S.-Y. Park, S. Kim and J.-W. Jhoo, J. Biol. Sci., 2014, 21, 427-435.

35 T. Wallerath, T. Kunt, T. Forst, E. I. Closs, R. Lehmann, T. Flohr, M. Gabriel, D. Schäfer, A. Göpfert and A. Pfützner, Nitric Oxide, 2003, 9, 95-102.

36 S. Davies, E. Stewart, G. Huesmann, N. Skaer, S. Maddrell, N. Tublitz and J. Dow, Am. J. Physiol.: Regul., Integr. Comp. Physiol., 1997, 273, R823-R827.

37 A. Nussler, M. Di Silvio, T. Billiar, R. Hoffman, D. Geller, R. Selby, J. Madariaga and R. Simmons, J. Exp. Med., 1992, 176, 261-264.

38 H. P. T. Ammon, Phytomedicine, 2010, 17, 862-867.

39 W. Wu, M. Zhang, Y. Ren, X. Cai, Z. Yin, X. Zhang, T. Min and H. A. Wu, J. Agric. Food Chem., 2017, 65, 5561-5569.

40 W. Ruijun, W. Shi, X. Yijun, T. Mengwuliji, Z. Lijuan and W. Yumin, Int. J. Biol. Macromol., 2015, 72, 771-775.

41 M. Kopf, H. Baumann, G. Freer, M. Freudenberg, M. Lamers, T. Kishimoto, R. Zinkernagel, H. Bluethmann and G. Köhler, Nature, 1994, 368, 339-342. 